Annales Geophysicae (2002) 20: 191-202 (C) European Geophysical Society 2002

\title{
An assessment of the "map-potential" and "beam-swinging" techniques for measuring the ionospheric convection pattern using data from the SuperDARN radars
}

\author{
G. Provan ${ }^{1}$, T. K. Yeoman ${ }^{1}$, S. E. Milan ${ }^{1}$, J. M. Ruohoniemi ${ }^{2}$, and R. Barnes ${ }^{2}$ \\ ${ }^{1}$ Department of Physics and Astronomy, University of Leicester, University Road, Leicester LE1 7RH, UK \\ ${ }^{2}$ Applied Physics Laboratory, John Hopkins University, Laurel, Maryland, USA
}

Received: 19 February 2001 - Revised: 1 October 2001 - Accepted: 3 October 2001

\begin{abstract}
The SuperDARN HF coherent scatter radars (Greenwald et al., 1995) provide line-of-sight (1-o-s) velocity measurements of ionospheric convection flow over the polar regions of the northern and southern hemispheres. A number of techniques have been developed in order to obtain 2-D plasma flow vectors from these 1-o-s observations. This study entails a comparison of the ionospheric flow vectors derived using the "map-potential", and "beam-swinging" techniques with the vectors derived using the "merging" technique. The merging technique is assumed to be the most accurate method of deriving local flow vectors from 1-o-s velocities. We can conclude that the map-potential model is significantly more successful than the beam-swinging technique at estimating both the magnitude and the direction of the largescale ionospheric convection flow vectors. The quality of the fit is dependent on time of day, with vectors observed at low latitudes in the dawn sector agreeing most closely with the merged vector flow pattern.
\end{abstract}

Key words. Ionosphere (plasma convection; instruments and techniques) - Radio science (instruments and techniques)

\section{Introduction}

Coherent scatter radars have provided measurements of ionospheric convection for almost thirty years. Individually, such radars make 1-o-s (1-o-s) velocity measurements of the plasma flow in the radar look direction. In the past, three VHF coherent radars, the Scandinavian Twin Auroral Radar Experiment (STARE) (Greenwald et al., 1978), the Sweden and Britain Radar-auroral Experiment (SABRE) (Nielsen et al., 1983) and the Bistatic Auroral Radar System (BARS) (André et al., 1988), have calculated "true" bistatic merged vectors by combining 1-o-s vectors obtained from different radars with overlapping fields-of-view. However, any measurement of E-region irregularities made by these VHF co-

Correspondence to: G. Provan (gp3@ion.le.ac.uk) herent radars is limited to the ion acoustic speed (Nielsen and Schlegel, 1983, 1985; Kofman and Nielsen, 1990) although this speed will increase nonlinearly with plasma drift velocity (Robinson, 1986). Subsequently, the F-region of the ionosphere was studied by the Polar Anglo-American Conjugate Experiment (PACE) at Goose Bay and Halley (Ruohoniemi et al., 1989). These single radars could only provide the 1-o-s velocity component of the plasma motion, as the individual radar fields-of-view do not overlap. For the PACE radars the transverse velocity component was obtained using data from these single radars by a beam-swinging technique (Villain et al., 1987; Ruohoniemi et al., 1987; 1989). Yeoman et al. (1992) assessed the beam-swinging technique as used to study E-region irregularity drift patterns with data from the SABRE radars. They found that both curvature and gradient in the flow vectors will cause errors in the velocity estimates, with $30 \%$ or more of the beam-swinging derived velocities lying outside a cone of half-width $30^{\circ}$ around the merged SABRE drift velocities. Freeman et al. (1991) studied vectors derived from the beam-swinging technique using a simulation of a 16-beam, single-station radar, comparing the simulation results with the results expected from a two-beam radar model. They found that although large-scale flows were in general reproduced well, curvature of the flow resulted in error in the beam-swung derived vectors, especially if the radius of the curvature of the flow structure had a scale size equal to, or less than, the radar field-of-view.

Concerns about the accuracy of flow vectors derived using the beam-swinging technique on data from single-station radars was one of the driving forces behind the SuperDARN radars (Greenwald et al., 1995) which have come into operation over the last few years. These are HF coherent radars mainly observing F-region scatter. The radars are arranged in pairs such that observation in a common volume is bidirectional. As with the VHF radars, 2-D flow vectors can be resolved unambigiously by merging 1-o-s velocity measurements from two radars at the beam intersections, assuming that each 1-o-s velocity is a component of the plasma velocity vector (Greenwald et al., 1995). Unlike E-region irregulari- 


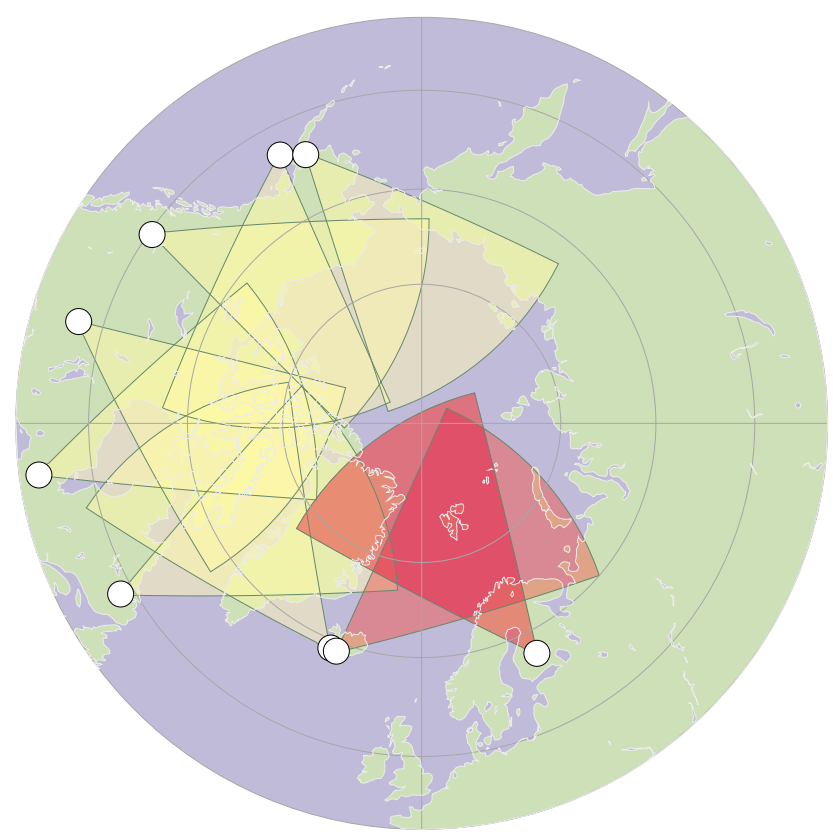

Fig. 1. The fields-of-view of the Northern hemisphere SuperDARN radars. The CUTLASS radars at Pykkvibær and Hankasalmi are shaded red.

ties, the velocity of the F-region irregularities is not limited by the sound speed of the plasma, but moves with the convective $\boldsymbol{E} \times \boldsymbol{B}$ ambient plasma drift velocity. Thus the 2-D merged vectors obtained from the HF radars can serve to map the plasma convection.

Merging relies on two or more radars having overlapping fields-of-view and observing backscatter simultaneously at the same position. A great portion of the fields-of-view of the radar systems is viewed by one radar only and, even where the radar fields-of-view do overlap, it is not uncommon for one radar to observe backscatter and not the other. The data, which cannot be used directly to provide merged vectors, can still provide a wealth of information about the ionospheric flows. In response to this the "map-potential" model (Ruohoniemi and Baker, 1998) was developed, aiming to utilize all available data from the SuperDARN radars to deduce the global convection pattern. As yet, the fieldsof-view of the SuperDARN radars do not have global coverage and the operating radars do not observe backscatter at all range gates at all times. To deduce a global convection pattern, the observed 1-o-s velocities from all the SuperDARN radars have to be combined with data from a statistical model (Ruohoniemi and Greenwald, 1996), to produce "fitted" flow vectors and a global convection model that is in best agreement with the observed 1-o-s velocities.

The map-potential technique is becoming the standard technique for determining global ionospheric flow; no work assessing its accuracy has yet been published, however. This paper involves a statistical study using data from the CUTLASS HF bistatic coherent scatter radars at Hankasalmi, Finland and Pykkvibær, Iceland (part of the SuperDARN net- work of HF radars), to assess the flow vectors derived by both the beam-swinging technique and the map-potential model, with the 2-D $\boldsymbol{E} \times \boldsymbol{B}$ drift velocities obtained by directly merging velocity measurements from the two radar systems, in order to quantitatively assess the accuracy of the map-potential technique and compare it with the beam-swinging method. Here we use the 1998 map-potential technique; however several improvements have been made to the technique since that time (Shepherd and Ruohoniemi, 2000). A perfect agreement between the vectors derived by the merging and map-potential techniques is not expected due to HF noise and misidentified ground scatter contaminating the l-o-s velocity data. Such noise can usually be identified in a case study but not in a large statistical study. There is also a difference in the applicability of the merge and the map-potential technique. The merging technique aims to derive the optimum local solution. The map-potential technique derives largescale solutions, with the data being median filtered before being "fitted" to a spherical harmonic expansion of the electrostatic potential (see Sect. 2.3). Thus the merging technique can show sources and sinks in the flow; this behaviour is not consistent with a potential solution, however.

\section{Data and data analysis techniques}

\subsection{Instrumentation}

The intention of the present study is to assess the accuracy of the beam-swinging technique and the map-potential model in estimating 2-D flow vectors of ionospheric irregularities, these irregularities moving at the convective $\boldsymbol{E} \times \boldsymbol{B}$ drift velocity over an extended region of the high-latitude ionosphere. The measured drift velocity vectors are estimated on the basis of bistatic coherent HF radar measurements provided by the SuperDARN radars at Hankasalmi and Pykkvibær. The phase velocity of irregularity drifts detected at HF, which is measured primarily in the F-region at heights of $150-600 \mathrm{~km}$, is dominated by the contribution from the large-scale drifts of the ambient plasma driven, for example, by the gradient drift instability (Fejer and Kelley, 1980), and should not differ substantially from the $\boldsymbol{E} \times \boldsymbol{B}$ drift velocity (Villain et al., 1985; Ruohoniemi et al., 1987; Davies et al., 1999, 2000).

CUTLASS is a bistatic HF coherent radar, with stations in Finland and Iceland, and forms part of the international SuperDARN chain of HF radars (Greenwald et al., 1995). The fields-of-view of the Northern hemisphere SuperDARN radars are illustrated in Fig. 1. The CUTLASS radars at Pykkvibær and Hankasalmi are shaded red. Each radar of the system is a frequency agile $(8-20 \mathrm{MHz})$ radar, routinely measuring the 1-o-s Doppler velocity and the spectral width and backscattered power of ionospheric plasma irregularities. The radars each form 16 beams of azimuthal separation $3.24^{\circ}$. Each beam is gated into 75 range bins, each of length $45 \mathrm{~km}$ in standard operations when the dwell time for each beam is either 3 or $7 \mathrm{~s}$ giving a full 16 beam scan, covering 
$52^{\circ}$ in azimuth and over $3000 \mathrm{~km}$ in range (an area of over $4 \times 10^{6} \mathrm{~km}^{2}$ ), every 1 or $2 \mathrm{~min}$. Common-volume data from the two stations can be combined to provide convection velocities perpendicular to the magnetic field. This dataset is supplemented by upstream IMF data from the WIND satellite (Lepping et al., 1995).

\subsection{Merging}

The northern hemisphere SuperDARN radars are arranged in 6 radar pairs, each pair allowing simultaneous l-o-s plasma drift measurements from two different directions in a common field-of-view. As each radar sounds along 16 beams, a $16 \times 16$ grid of overlapping measurements is available from each pair. These measurements can be combined, using a process called "merging", to provide a maximum of 2562-D plasma flow vectors per-radar-pair. Under optimum conditions, direct mapping of ionospheric convection in the Northern hemisphere can be extended to more than $12 \mathrm{~h}$ of MLT. In practice, backscatter is not available within all merge cells and fewer than the maximum 256 vectors per-radar-pair are calculated (Hanuise et al., 1993).

\subsection{The map-potential model}

In an effort to improve the coverage available from the merge technique the "map-potential" technique, was developed by Ruohoniemi and Baker (1998). The authors argued that, even if merged vectors cannot be determined due to poor coverage from one of a pair of radar fields-of-view, all the available 1-o-s velocities serve to constrain the possibilities for the large-scale convection velocity. The convection pattern that is most consistent with the measurements can be determined by a mathematical fitting technique involving all the available l-o-s data. This is the basis for the map-potential technique, described by Ruohoniemi and Baker (1998) as "a method of filtering, combining and reducing data from the SuperDARN radars which optimizes the fitting of largescale convection patterns". This philosophy is similar to the approach taken in the derivation of some statistical convection models (i.e. Ruohoniemi and Greenwald, 1996; Weimer, 1995) and by the assimilative mapping of electrodynamics (AMIE) procedure (Richmond and Kamide, 1988).

Initially the 1-o-s velocity data from each radar are filtered by performing a "boxcar" filter involving both spatial and temporal filtering. The smoothed data is then mapped onto a global grid which is $1^{\circ}$ in latitude (approx. $111 \mathrm{~km}$ projected onto the surface of the Earth) and as close as possible to $111 \mathrm{~km}$ in longitude. The gridded data from each radar is then combined into a single file, using a temporal averaging period which can be as short as the scan repetition rate. The combined l-o-s velocity data for a period is then "fitted" to an expansion of the electrostatic potential in spherical harmonic functions (e.g. Jackson, 1962; Ruohoniemi and Baker, 1998; Bristow et al, 1998).

The solution is constrained by folding in information from a statistical model (Ruohoniemi and Greenwald, 1996),

\section{SUPERDARN PARAMETER PLOT}

Merged vectors 25 Feb 1998

(a)

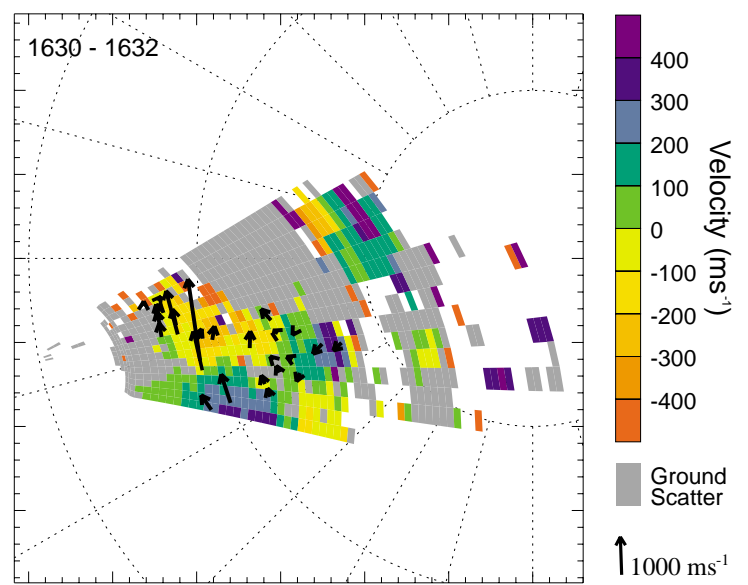

Beamswung vectors vectors

(b)

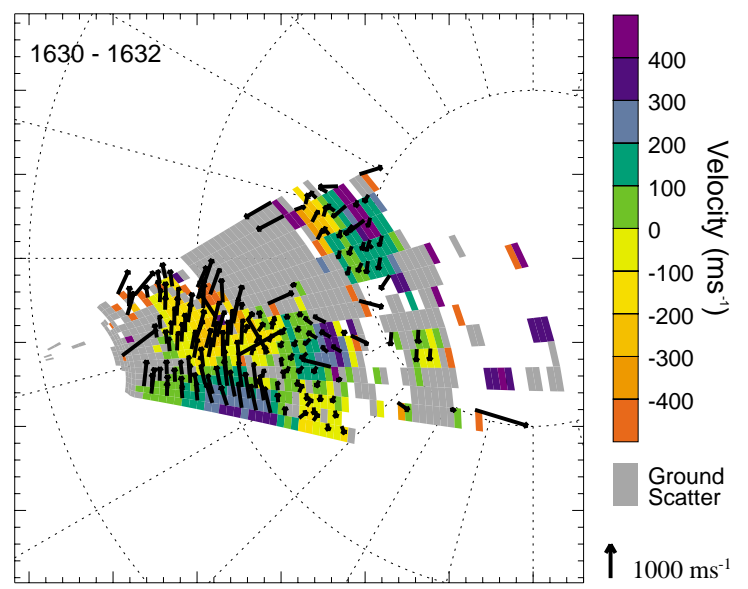

Fig. 2. (a) Polar plot of 1-o-s velocities detected by the Hankasalmi radar on 25 February 1998, 16:30 UT. The velocity is colour coded with red (negative) velocities indicating motion away from the radar and blue/green (positive) velocities indicating motion toward the radar. Overlayed are merged vectors calculated using 1-o-s velocities from the Hankasalmi and Pykkvibær radars for the same period. (b) Polar plot of 1-o-s velocities detected by the Hankasalmi radar on 25 February 1998, 16:30 UT (as in Fig. 2a). Overlayed are beamswung vectors calculated using l-o-s velocities from the Hankasalmi radar for the same period.

keyed to the IMF conditions. The order $l$ and degree $m$ of the expansion determine the spatial filtering performed on the velocity data. In this statistical study we use $l=m=4$ for all days. In the map-potential technique, as the order of the fitting is increased, the statistical model is sampled at more points to constrain the additional terms of the expansion but the weight assigned to each of the samples is reduced in inverse proportion. In this way the 'effective' contribution of the statistical model to the "fitted" solution does not increase with order (Shepherd and Ruohoniemi, 2000).

The map-potential technique outputs a number of different 
types of velocity flow vectors; in this study we are concerned with two of these. "Fitted" vectors are produced which represent the l-o-s velocity vectors which have been "fitted" to the global convection pattern. "True" vectors are also produced by combining the transverse component of the "fitted" velocity vectors with the measured l-o-s velocity, thus allowing the small-scale variations of the 1-o-s velocity to be recovered. Several quality-of-fit parameters are also obtained from the "fitting" procedure, including the "reduced" chi-squared $\left(\chi_{r}^{2}\right)$ obtained by dividing $\chi^{2}$ by the number of degrees of freedom in the fitting. If the measurements are physical (i.e. can be represented as the gradient of a scalar potential) and the measurements are distributed normally, $\chi_{r}^{2}$ gauges the degree to which the distribution of the offsets (i.e. the differences between the "fitted" and measured velocities) is consistent with the uncertainties assigned to the measurements (Ruohoniemi and Baker, 1998).

\subsection{The beam-swinging technique}

The 1-o-s velocity measured by a single radar beam provides only one component of the plasma flow. When measurements from several beams are combined it is possible to estimate the flow component perpendicular to the radar beam and thus derive the magnitude and angle of the plasma flow. This is the basis of "beam-swinging", a technique first developed in the 1960s. The beam-swinging technique used here attempts to derive a value for the transverse velocity component, $V_{\phi}$, by assuming that the flow along a contour of constant L-shell is constant with respect to the L-shell; thus the 1-o-s velocity varies simply as a cosine of the angle that the radar look direction makes with the L-shell contour. This assumption was first described by Ruohoniemi et al. (1989). It is described by Eq. (1), where $V_{\text {flow }}$ is the velocity at which the plasma is flowing at an azimuthal angle $\theta_{\text {flow }}$. If the flow is observed by a radar beam located at an angle $\theta_{\text {radar }}$ to the L-shell, the observed l-o-s velocity, $V_{1-\mathrm{O}-\mathrm{S}}$, is given by

$V_{\text {l-o-s }}=V_{\text {flow }} \cos \left(\theta_{\text {radar }}-\theta_{\text {flow }}\right)$

L-o-s velocities observed by any number of radar beams can be used to determine the flow along a particular L-shell. The obtained vectors are resolved into components parallel and perpendicular to the radar look direction over the full fieldof-view of the radar. The derived perpendicular component is then combined with the measured parallel (line-of-sight) component to produce a corrected vector. This allows the small-scale variations of the 1-o-s velocity to be recovered after the smoothing effects of the large-scale L-shell fits. From here, on this process will be referred as "beam-swinging" and the product as "beam-swung velocities".

\section{The statistical study}

In this study we compare vectors derived by the beamswinging and map-potential techniques with vectors derived using the merging algorithm. The merged vectors are assumed to be the most accurate, as these vectors are based purely on radar observations and no prior assumptions are made when deriving them. The statistical database for this study comprises 164 days of data from 1998 when the CUTLASS radars were run in normal mode (operating all 16 beams with 2 min resolution and $45 \mathrm{~km}$ range gates) for the entire day. We merged the 1-o-s velocity data from the two radars for all the selected days, resulting in a total of $\sim 145000$ merged data points, which form the basis for our statistical study. Figure 2 illustrates an example of the radar scan, showing Hankasalmi 1-o-s velocities obtained from the 25 February 1998, 16:30 to 16:32 UT. L-o-s velocity is colour coded with negative velocities (red/yellow) representing flow away from the radar and positive velocities (blue/green) representing flows towards the radar. Overlaid on the 1-o-s velocity are merged velocity vectors obtained by merging data for the Hankasalmi and Pykkvibær radars from the same period.

Beam-swung vectors were obtained from the 1-o-s velocity data observed by the Finland radar using the method outlined in Sect. 2.4. Each L-shell in the beam-swinging algorithm was $2^{\circ}$ wide and the beam-swinging algorithm was only performed if there were three or more data points in any given L-shell. The error of the velocity magnitude of every beam-swung vector was calculated for each L-shell. Figure $2 \mathrm{~b}$ shows the beam-swung vectors obtained for the 25 February 1998, 16:30 to $16: 32$ UT. For the statistical study we compared each merged data point with its nearest beamswung data point.

L-o-s velocity data from the Hankasalmi and Pykkvibær radars were used to obtain 2-D flow vectors using the mappotential model described in Sect. 2.3. Both "fitted" and "true" 2-D flow vectors were obtained for each 2 min scan of the 164 days of the statistical study. The statistical model, which forms part of the map-potential routine, is dependent on the prevailing IMF conditions. Data from the WIND satellite was used to measure the daily IMF conditions, the delay time between when the solar wind reaches the satellite and when it impinges on the subsolar magnetopause was calculated using the method of Lester et al. (1993). Figure 3a presents the "fitted" vectors calculated using data from the Hankasalmi radar for 25 February 1998 at 16:30 UT, while Fig. $3 \mathrm{~b}$ shows the "true" vectors for the same period. Again, for the statistical study we compared each merged vector with its nearest vector as calculated by the map-potential model.

\section{Results of the statistical comparison}

\subsection{Comparison between merged and beam-swung vectors}

Initially we compared the flow direction and the flow magnitude of the vectors calculated using the beam-swinging technique with those calculated using the merging technique for the 164 days of the statistical study. Figure 4 presents a scatter plot of the directions of all the flow vectors calculated using the beam-swinging and the merging techniques. 


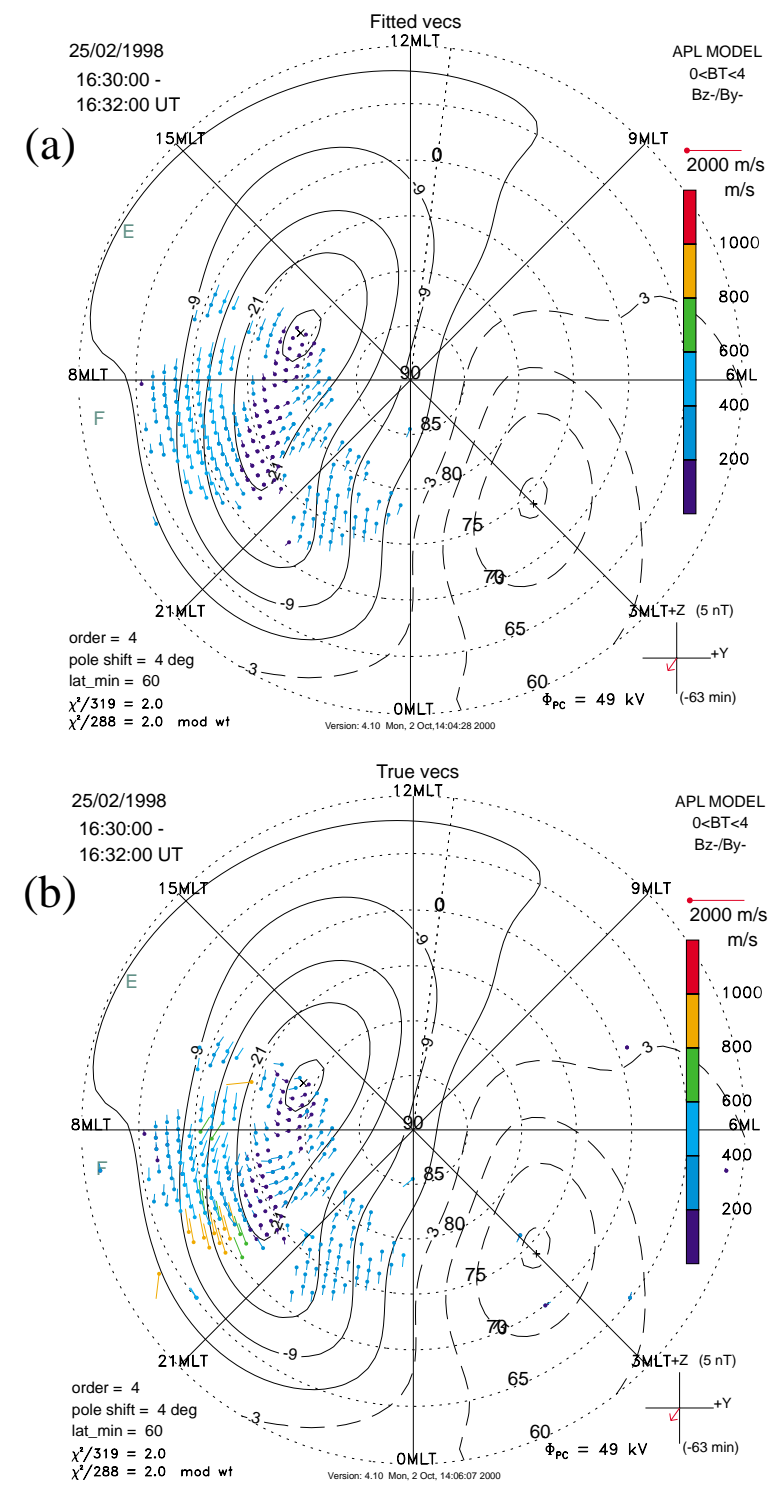

Fig. 3. (a)"Fitted" map-potential vectors for 25 February 1998, 16:30 to 16:32 UT. The velocity data are scaled to the length of the reference arrow and are also colour-coded by magnitude. Solid (dotted) contours are associated with negative (positive) values of the electrostatic potential, and the contour interval is $6 \mathrm{kV}$. The vectors are obtained by fitting the 1-o-s velocity data and data from a statistical convection pattern to a low-order expansion $(L=4)$ of the electrostatic potential in spherical harmonics. The predictions of the statistical convection model are based on the prevailing IMF conditions, with IMF measurements being made by the WIND spacecraft. A schematic of the IMF vectors in the GSM $Y-Z$ plane is shown in the bottom right hand corner. There is a 63 min delay time between detection of the solar wind by the WIND spacecraft and its impingement on the subsolar magnetopause. (b) "True" map-potential vectors for 25 February 1998, 16:30 to $16: 32 \mathrm{UT}$

The normalized occurrence distribution of the angles measured by both techniques is also shown. Angles are measured clockwise from geomagnetic north. In all cases the $45^{\circ}$ line represents the idealized case where the beam-swinging technique perfectly reproduces the merged velocity direction measurements. The velocity direction plot shows two distinct clusters of points. One cluster is around $90^{\circ}$, due to eastward flow measured by the radar in the dawn convection cell; the other cluster is around $270^{\circ}$, due to westward flow in the dusk convection cell. This clustering is due to the beam-swinging technique assuming the plasma flow to be L-shell aligned. The beam-swinging derived velocities tend to cluster at higher angles than the merged velocities, as demonstrated by the normalized occurrence distribution of data points, which peaks at $90^{\circ}$ and $270^{\circ}$ for the merged angles, and at $95^{\circ}$ and $285^{\circ}$ for the beam-swung angles. The merging algorithm appears to preferentially detect flow in the dusk convection cell, with almost twice as many data points being detected at the dusk sector peak (10642 data points) compared to the dawn sector peak (5212 data points). The beam-swung algorithm also detects almost $40 \%$ more data points in the dusk sector peak (9755 data points) compared 
Table 1. A comparison of velocity direction calculated using the beam-swung and map-potential techniques with the velocity direction of merged vectors

\begin{tabular}{lc}
\hline Velocity direction & $\begin{array}{c}\% \text { within } 45^{\circ} \text { cone } \\
\text { of merged angles }\end{array}$ \\
\hline All beam-swung angles & 48 \\
Beam-swung angles with rms error $<150 \mathrm{~m} / \mathrm{s}$ & 61 \\
All fitted map-potential angles & 65 \\
Fitted map-potential angles with $\chi^{2}<1.5$ & 64 \\
All true map-potential angles & 66 \\
Beam-swung vectors observed at dusk between $65^{\circ}$ and $70^{\circ}$ magnetic lat. & 75 \\
True map-potential observed at midday between $65^{\circ}$ and $70^{\circ}$ magnetic lat. & 84 \\
\hline
\end{tabular}

\section{Comparison between merged and beam_swung angles}

Total number of data points 143401 .

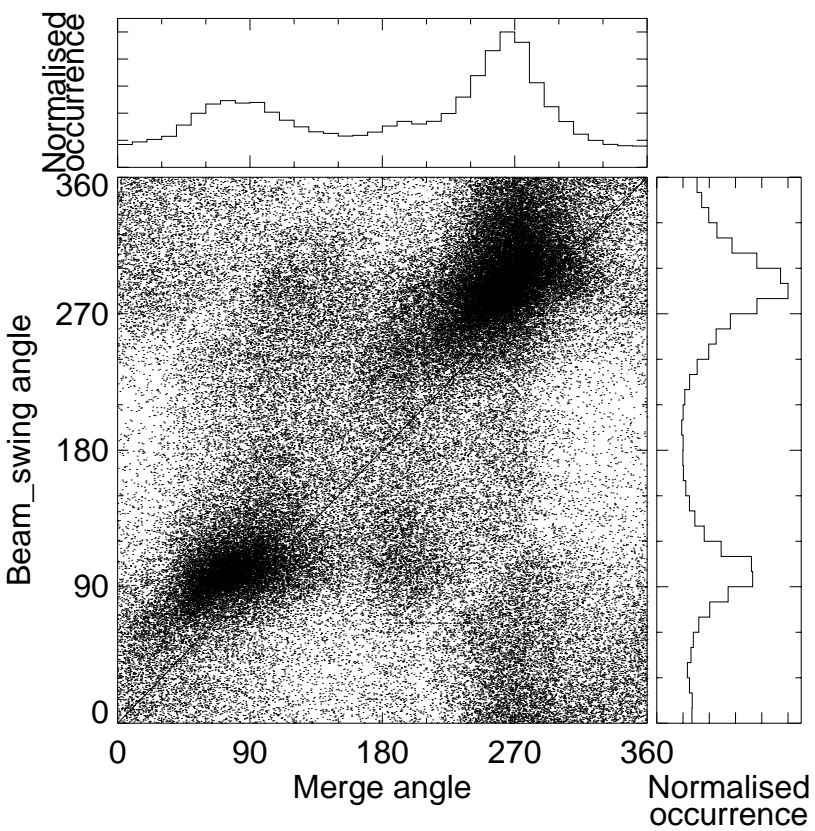

Fig. 4. Comparison between merged and beam-swung velocity directions. Also shown are the normalized occurrence distributions of the angles.

to the dawn sector peak (7047 data points). In general, the two clusters of points show a greater range in the velocity direction determined by the merging algorithm than by the beam-swinging technique, especially in the flow measured in the dawn convection cell.

Table 1 summarises the results of the statistical comparison between vector direction calculated by the various techniques in this study. $48 \%$ of beam-swung derived velocity directions lie inside a cone of $45^{\circ}$ half-width around the merged velocity estimates. When beam-swung data points which have been filtered, so that only the data points which have an rms error in their velocity magnitude of $15 \mathrm{~m} / \mathrm{s}$ or less

\section{Comparison between merged and beam_swung velocities}

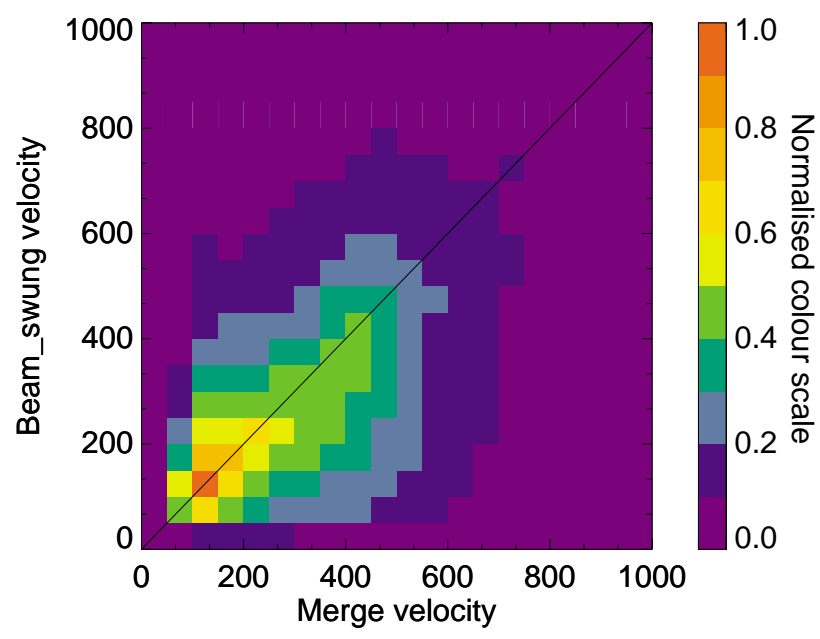

Fig. 5. Comparison between merged and beam-swung velocity magnitudes. The normalized occurrence distribution of data points is colour coded with red indication region of most data points and blue indication region of fewest data points.

(compared to the best-fit velocity measured at that L-shell), then $61 \%$ of the beam-swung derived velocity estimates lie inside a cone of $45^{\circ}$ half-width around the merged velocity estimate.

Figure 5 presents a comparison of the magnitude of the flow vectors calculated using the merged and beam-swung techniques. The occurrence of velocity magnitude is colour coded with red representing the region of greatest occurrence and blue representing the region of least occurrence. Again the $45^{\circ}$ line represents the idealized case where the beamswinging technique perfectly reproduces the merged velocity estimates. The velocities estimated by both techniques are mainly between 50 and $300 \mathrm{~m} / \mathrm{s}$ and are centred on the $45^{\circ}$ line.

Table 2 summarises the statistical comparison between vector magnitudes calculated by the various techniques employed in this study. $31 \%$ of the velocity vectors estimated by 
Table 2. A comparison of the magnitude of beam-swung and map-potential vectors with magnitude of merged vectors

\begin{tabular}{lcc}
\hline Velocity magnitude & $\begin{array}{c}\text { \% of vectors with } \\
\text { magnitude within } \\
\text { 25\% of merged vector }\end{array}$ & $\begin{array}{c}\text { \% of vectors with } \\
\text { magnitude within } \\
50 \% \text { of merged vectors }\end{array}$ \\
\hline All beam-swung vectors & 31 & 54 \\
All fitted map-potential vectors & 41 & 66 \\
All true map-potential vectors & 49 & 73 \\
$\begin{array}{l}\text { True map-potential vectors } \\
\text { observed at midday between 65 } \\
\text { and } 70^{\circ} \text { magnetic latitude }\end{array}$ & 50 & 74 \\
\hline
\end{tabular}

Table 3. Percentage of beam-swung vectors which are within a cone of $45^{\circ}$ around the merged angles, as a function of magnetic local time and magnetic latitude

\begin{tabular}{ccccc}
\hline Mag. & $03: 00-09: 00$ & $09: 00-15: 00$ & $15: 00-21: 00$ & $21: 00-03: 00$ \\
Latitude & MLT & MLT & MLT & MLT \\
$60^{\circ}-65^{\circ}$ & No data & No data & No data & No data \\
$65^{\circ}-70^{\circ}$ & 69 & 67 & 75 & 59 \\
$70^{\circ}-75^{\circ}$ & 52 & 53 & 55 & 48 \\
$75^{\circ}-80^{\circ}$ & 33 & 37 & 32 & 35 \\
$80^{\circ}-85^{\circ}$ & 21 & 32 & 28 & 29 \\
$85^{\circ}-90^{\circ}$ & No data & No data & No data & No data \\
\hline
\end{tabular}

the beam-swinging algorithm have a magnitude that is within $25 \%$ or $50 \mathrm{~m} / \mathrm{s}$ (whichever is larger) of the magnitude estimated by the merging algorithm.

A study was performed to see whether the quality of the fit of the data was dependent upon time of day or the latitude at which the 1-o-s vectors were observed. The data has been divided into four different time intervals, night (21:00-03:00 MLT), dawn (03:00-09:00 MLT), midday (09:00-15:00 MLT) and dusk (15:00-21:00 MLT) with six different latitude bins from $60^{\circ}$ to $90^{\circ}$. Table 3 presents the percentage of beam-swung vectors which are within a cone of $45^{\circ}$ around the merged angles as a function of local time and magnetic latitude. These results are also depicted in Fig. 6. The colour bar is normalized, with red representing the region where there is the highest percentage of map-potential vectors within the same flow quadrant as the merged vectors and blue representing the region of lowest percentage of merged vectors within the same flow quadrant as the merged vectors. The results show that the beamswinging technique is most successful at predicting flow angles in the dusk and dawn sectors at low latitudes. Overall, we found that the beam-swinging technique was most successful at predicting the angle of plasma flow at low latitude in the dusk sector, with $75 \%$ of the vectors being in the correct flow quadrant as compared with $48 \%$ of the data points when using all the available data (Table 1). The beamswinging technique was least successful at estimating the correct flow quadrant at high latitude in the dawn sector; here only $21 \%$ of the angles were in the correct flow quadrant.
Comparison between merged and beam-swung velocity direction as a function of latitude and local time.

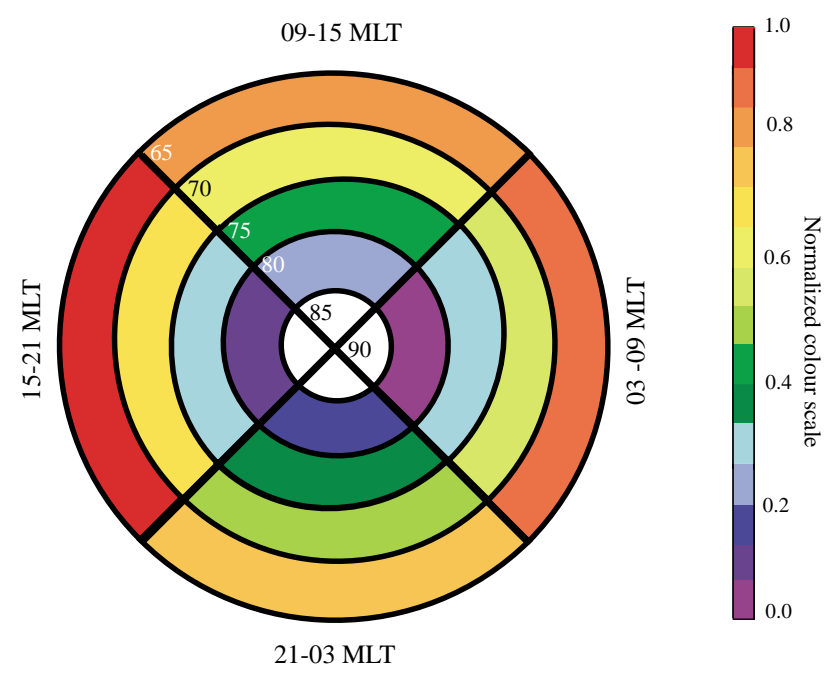

Fig. 6. Comparison between merged and beam-swung velocity directions, as a function of magnetic latitude and magnetic local time. The diagram is colour coded with red indicating the region where there is the highest percentage of beam-swung vectors within the same flow quadrant as the merged vectors, and blue representing the region where there is the lowest. 
Table 4. Percentage of true map-potential vectors which are within a cone of $45^{\circ}$ around the merged angles, as a function of magnetic local time and magnetic latitude

\begin{tabular}{ccccc}
\hline Mag. & $03: 00-09: 00$ & 09:00-15:00 & 15:00-21:00 & 21:00-03:00 \\
Latitude & MLT & MLT & MLT & MLT \\
$60^{\circ}-65^{\circ}$ & No data & No data & No data & No data \\
$65^{\circ}-70^{\circ}$ & 80 & 84 & 83 & 70 \\
$70^{\circ}-75^{\circ}$ & 69 & 78 & 76 & 65 \\
$75^{\circ}-80^{\circ}$ & 51 & 60 & 53 & 56 \\
$80^{\circ}-85^{\circ}$ & 30 & 30 & 27 & 25 \\
$85^{\circ}-90^{\circ}$ & No data & No data & No data & No data \\
\hline
\end{tabular}

\section{Comparison between merged and true map potential angles}

\section{Total number of data points 143401 .}

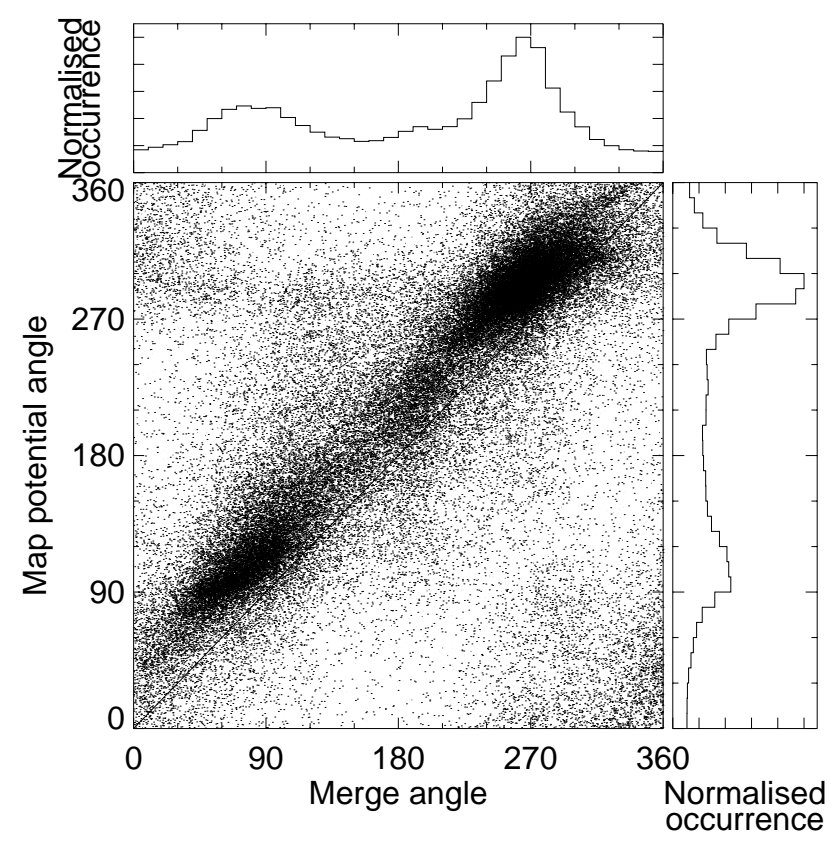

Fig. 7. Comparison between merged and "true" map-potential velocity directions. Also shown are the normalized occurrence distributions of the angles.

\subsection{Comparison between merged and map-potential vec-} tors

Having compared the merging technique with the beamswinging technique, we proceed to compare the merging technique with the map-potential model. Figure 7 presents the scatter plot of the directions of the merged flow vectors with the "true" flow vectors, the normalized occurrence distributions of the angles measured by both techniques are also shown. As before, angles are measured clockwise from geomagnetic north and the $45^{\circ}$ line represents the idealized case where the map-potential technique perfectly reproduces the merged velocity estimates. As with the comparison between the merged and beam-swung angles, there are two main clusters of points, one situated around $90^{\circ}$, the other around $270^{\circ}$. However, now there seems to be a general clustering of points around the $45^{\circ}$ line for all angles, although there appears to be an offset of about $20^{\circ}$ between the velocity directions estimated by the map-potential and the merge techniques. The peak in the occurrence of data points in the dusk sector (14871 data points) is more than twice as large as the peak in the occurrence of data points in the dawn sector (6135 data points).

We studied the cumulative percentage of map-potential derived velocity estimates within a given angular difference to the merged velocities. We found that $65 \%$ of the angles derived using the "fitted" map-potential model lay inside a $45^{\circ}$ cone around the merged velocity estimates; for the "true" vectors this value was $66 \%$ (Table 1 ). So there was no significant difference in the ability of the "fitted" and "true" vectors to correctly predict the correct flow quadrant. However, these values were a significant improvement on the beam-swinging technique, where only $48 \%$ of the un-filtered velocity estimates and $61 \%$ of the filtered velocity estimates were in the correct flow quadrant.

Each scan of data for the map-potential model has a $\chi_{r}^{2}$ value associated with it, which is a measurement of the goodness of the fit. We filtered the "fitted" map-potential angles only including data which had an associated $\chi_{r}^{2}$ value of 1.5 or less. When comparing the filtered map-potential angles, with the merged velocity direction, only $64 \%$ of the filtered map-potential angles lay within a cone of $45^{\circ}$ half-widths around the merged angles (Table 1). It would appear that the $\chi_{r}^{2}$ value for each scan of the map-potential model is not significant when determining the algorithm's ability to accurately predict the correct flow quadrant.

Figure 8 presents a comparison of the magnitude of the flow vectors calculated using the merged and "true" mappotential techniques. The occurrence of velocity magnitude is colour coded with red representing the region of greatest occurrence and blue representing the region of least occurrence. The velocities estimated by both techniques are mainly between 50 and $300 \mathrm{~m} / \mathrm{s}$ and are centred on the $45^{\circ}$ line, indicating a good fit between the velocity magnitudes estimated by the two techniques. However, the velocity magnitudes estimated by the map-potential model are slightly 


\section{Comparison between merged and map_potential velocities}

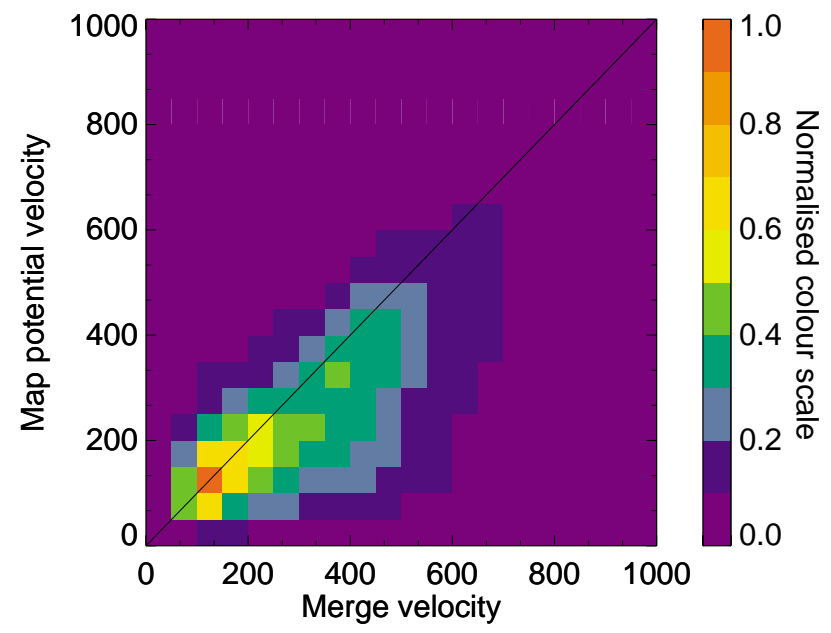

Fig. 8. Comparison between merged and "true" map-potential velocity magnitude. The normalized occurrence distribution of data points is colour coded with red indicating regions of most data points and blue indicating region of fewest data points.

smaller than those estimated by the merging algorithm.

A comparison was performed between the merged and the "fitted" and "true" map-potential velocity estimates, studying the cumulative percentage occurrence in the percentage difference in the velocity magnitudes estimated by the merging algorithm as compared with the velocity magnitudes estimated by the map-potential model. $41 \%$ of the flow vectors estimated by the map-potential model and the merging algorithm have magnitudes that are within $25 \%$ or $50 \mathrm{~m} / \mathrm{s}$ (whichever is larger) of each other (Table 2), as compared with $49 \%$ of the "true" velocity vectors.

Finally, a study was performed to see whether the quality of the fit of the data was dependent upon time of day or the latitude at which the 1-o-s vectors were observed. Table 4 presents the percentage of map-potential vectors which are within a cone of $45^{\circ}$ around the merged angles, calculated separately for six longitude bins in four time separate time intervals, dawn (03:00-09:00 MLT), midday (09:0015:00 MLT), dusk (15:00-21:00 MLT) and night (21:0003:00 MLT). There were no vectors to compare between $60^{\circ}$ and $65^{\circ}$ so the latitude runs from $65^{\circ}$ to $90^{\circ}$. The results presented in Table 4 are also depicted in Fig. 9. The colour bar is normalized, with red representing the region where there is highest percentage of map-potential vectors within the same flow quadrant as the merged vectors, and blue representing the region of lowest percentage of merged vectors within the same flow quadrant as the merged vectors. The results show that the map-potential model is most successful at predicting flow angles in the dusk and day sectors at low latitudes. Overall, we found that the map-potential technique was most successful at predicting the angle of plasma flow at low latitude in the day sector, with $84 \%$ of the vectors being
Comparison between merged and true map-potential velocity direction as a function of latitude and local time.

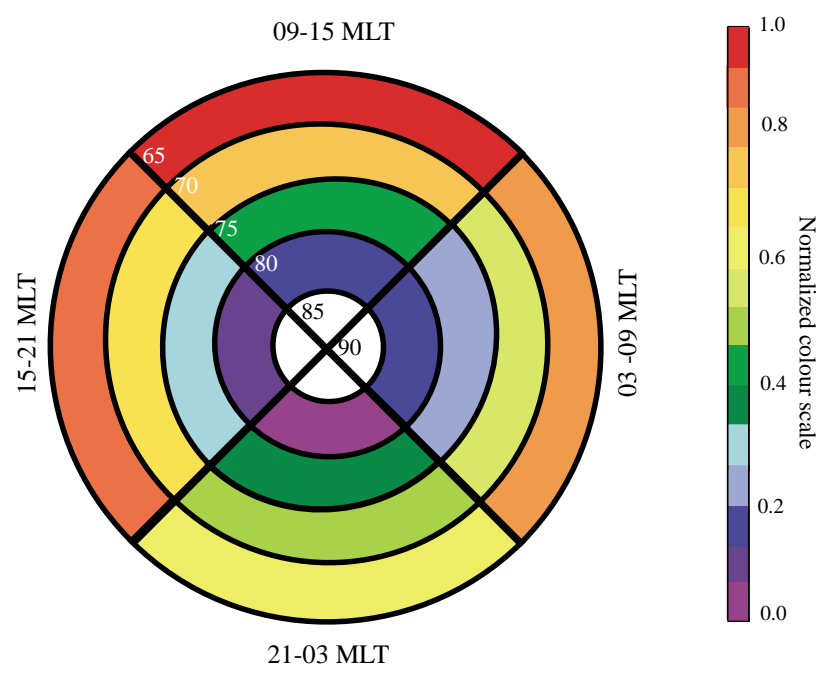

Fig. 9. Comparison between merged and "true" map-potential velocity directions, as a function of magnetic latitude and magnetic local time. The diagram is colour coded with red indicating the region where there is the highest percentage of beam-swung vectors within the same flow quadrant as the merged vectors, and blue representing the region where there is the lowest.

in the correct flow quadrant, as compared with $66 \%$ of the data points when using all the available data (Table 1). 50\% of the "true" map-potential velocities estimated at this time and latitude had a magnitude within $25 \%$ or $50 \mathrm{~m} / \mathrm{s}$ of the merged velocity magnitudes (Table 2). The technique was least successful at predicting the correct flow angle at high latitudes in the night sector; here only $25 \%$ of the vectors were in the correct flow quadrant.

\section{Discussion}

In this study we have used 1-o-s velociy data from the Finland (Hankasalmi) and Iceland East (Pykkvibær) bistatic coherent scatter radars, part of the SuperDARN network of HF radars, to assess the flow vectors derived by the beamswinging technique and the map-potential model, with the 2-D $\boldsymbol{E} \times \boldsymbol{B}$ drift velocities obtained by directly merging velocity measurements from the two radar systems. The statistical study was performed on 164 days of normal resolution ( $2 \mathrm{~min}$ ) data from the two radars. The merged velocity vectors were calculated using 1-o-s velocity vectors from both radars, a total of $\sim 145000$ merged vectors were obtained from the 164 days. These were compared with flow vectors calculated using the beam-swinging technique for the Finland (Hankasalmi) radar only, and vectors obtained using the map-potential model with 1-o-s data from the two radars. 
Figures 4 and 7 present scatter plots of the direction of the merged flow vectors with the beam-swung vectors and the "true" map-potential flow vectors, respectively. Both techniques result in two main clusters of points, one situated at $90^{\circ}$, due to eastward flow measured by the radar in the dawn convection cell, the other cluster is around $270^{\circ}$, due to westward flow in the dusk convection cell. However, when comparing the merged and the "true" map-potential vectors there is also a general clustering of points around the $45^{\circ}$ line, not present for the beam-swung vectors. This shows that the map-potential algorithm is capable of accurately determining non L-shell aligned convection flow which is poorly estimated by the beam-swinging technique as it makes incorrect assumptions about the flow patterns in these regions. This demonstrates that the map-potential technique, with its incorporated statistical model, makes much more realistic assumptions about the flow pattern than the simple beamswinging technique.

The flow angles estimated by both the beam-swinging and the map-potential techniques are offset by about $20^{\circ}$ to those calculated by the merging technique, representing an average southward tilt of the map-potential and beam-swung derived velocities as compared with the merged velocities in the dawn sector and, conversely, an average northward tilt in the dusk convection cell. At present we can offer no explanation for this offset. All three algorithms appear to preferentially detect flow in the dusk convection cell. However, whereas the map-potential model observed approximately $140 \%$ more data points in the dusk sector than the dawn sector, this was reduced to $100 \%$ for the merging algorithm and to only $40 \%$ for the beam-swinging algorithm.

We compared the cumulative percentage of the velocity directions derived by the beam-swinging and the map-potential techniques within a given angular difference to the merged velocity direction (see Table 1). $48 \%$ of the data points calculated by the beam-swinging technique were in the correct flow quadrant, as compared to $65 \%$ of the data calculated by the "fitted" map-potential model and $66 \%$ of the data points calculated by the "true" map-potential method. So although there was no significant difference in the ability of the "true" and "fitted" map-potential vectors to correctly predict the correct flow quadrant, the map-potential model resulted in a significant improvement in accurately predicting the flow angle of ionospheric vectors as compared with the beam-swinging technique.

We have attempted to utilise several quality flags in order to remove less accurate data but without success. When comparing the flow direction of the vectors calculated by the merged and beam-swung methods, we discarded all beamswung velocities with a rms error of more than $150 \mathrm{~m} / \mathrm{s}$. Of the remaining vectors, $61 \%$ of the data points accurately predicted the correct flow quadrant as compared to $48 \%$ of the data points when all the flow vectors where included. So, filtering the data using the rms error, results in a $13 \%$ improvement in the ability of the data to correctly predict the flow angle of the ionospheric flow. However the proportion of filtered beam-swung vectors that are within the correct flow quadrant is still less than those of the "true" map-potential vectors. When comparing the map-potential velocity estimates, we removed all the data points which had a $\chi_{r}^{2}$ greater than 1.5 associated with them. However, there was no significant difference in the ability of the vectors to predict the correct flow quadrant, suggesting that the $\chi_{r}^{2}$ parameter is not a particularly accurate quality-of-fit parameter but, rather, that the accuracy of the assumptions underlying the technique determines the fit quality.

Figures 5 and 8 present comparisons of the magnitude of the flow vectors calculated using the merged/beam-swung and the merged/map-potential techniques, respectively. The velocities estimated by all three techniques are mainly between 50 and $300 \mathrm{~m} / \mathrm{s}$. The velocity magnitudes estimated by the beam-swinging algorithm appear to be of the same magnitude as the velocity magnitudes estimated by the merging algorithm. Figure 8 would suggest that "true" velocities estimated by the map-potential model are slightly smaller than those estimated by the merging algorithm. This may be due to the spatial and temporal filtering performed on the mappotential vectors.

Table 2 presents a comparison of the magnitude of the beam-swung and "true" map-potential vectors with the magnitude of the merged vectors. $31 \%$ of the beam-swung vectors had a magnitude that was within $25 \%$ of the merged velocity magnitude as compared with $41 \%$ of the "fitted" and $49 \%$ of the "true" map-potential flow vectors. So "true" map-potential flow vectors are significantly more successful at predicting the magnitude of the plasma flow than the "fitted" map-potential vectors or the beam-swung vectors.

The map-potential model appears to be more successful at predicting both the flow angle and the magnitude of ionospheric convection flow than the beam-swinging technique. The quality of the fit of the data is also dependent upon time of day and the latitude at which the 1-o-s vectors were observed. We compared the percentage of "true" map-potential velocity vectors and beam-swung vectors which are within a cone of $45^{\circ}$ half-width around the merged angles for different magnetic local times and magnetic latitudes (Tables 3 and 4, Figs. 6 and 9). The results show that both the mappotential model and the beam-swinging technique are most successful at predicting flow angles at low latitudes. This is probably because ionospheric flow is more ordered at low latitudes than at high latitudes. However, although for the map-potential model the quality of the fit of data did not vary greatly between the dawn, midday and dusk sectors, the quality of the fit of the beam-swung vectors was more dependent on time of day, predicting the direction of ionospheric flows most accurately at low latitudes in the dawn and dusk sectors. At these times the radars are observing L-shell aligned flow which is much more ordered than flow observed at midday or midnight. The results show that the map-potential model is less dependent than the beam-swinging technique on flows being zonal in order to function well, which is to be expected considering that the map-potential technique uses a statistical model to make more realistic assumptions about the plasma flow than the simple assumptions made by 
the beam-swinging technique. Both the map-potential and the beam-swinging techniques perform poorly in the night sector, showing that the unstructured flow observed at such high latitude is difficult to reproduce by any technique which makes assumptions about the direction of plasma flow; no matter whether these assumptions involve predicting the flow to be zonal or are based on using a statistical model when determining the plasma flow pattern.

In this paper we have used the 1998 version of the mappotential technique. Over the past few years several changes have been made to the map-potential technique, as described in Shepherd and Ruohoniemi (2000). We have compared vectors derived by the map-potential and merging techniques. These two techniques are very different and perfect agreement between the vectors derived by them is not expected due to HF noise and misidentified ground scatter contaminating the 1-o-s velocity data. The merging technique aims to derive the best local solution while the map-potential technique derives global solutions. Thus the merging technique can show sources and sinks in the flow; however this behaviour is not consistent with a potential solution. Finally, in this paper, the merging technique is assumed to be the most accurate method of deriving flow vectors from 1-o-s velocities as the technique does not depend on a statistical model or make any assumptions about the direction of the plasma flow. However, the merging technique is still subject to the possible measurement errors outlined above and there is also the possibility of error if the angle separating the two merged $1-0-s$ velocity measurements is small.

The map-potential vectors were only obtained using 1-o-s flow vectors from one of the Northern hemisphere SuperDARN radar pairs. In reality the model is best run using all the available 1-o-s velocities from all six pairs of Northern hemisphere SuperDARN radars with the model being run on a case-by-case basis where parameters such as the order of fit and low-latitude boundary can be adjusted for the individual measurements. We would assume that, if the mappotential model used more 1-o-s velocities when calculating the convection flow vectors, the resulting vectors would be even more accurate. However, the authors are aware that this study is only using the map-potential model in regions where predicted flow vectors are most dependent on observed l-o-s velocity as these are the regions where it is possible to obtain merged flow vectors. Had we been able to perform a similar study of the map-potential vectors obtained further from the radar fields-of-view (and thus more dependent on the statistical model) the results might have been different.

Yeoman et al. (1992) assessed the beam-swinging technique as used to study E-region irregularity drift patterns with data from the SABRE radars. The L-shell "fitted" velocities were calculated under two different sets of constraints: a "loosely constrained" fit, where the radar data were required to fill at least five of the eight SABRE beams and the rms error of the least square fit of the L-shell was required to be less than $75 \mathrm{~m} / \mathrm{s}$. In addition a set of "tightly constrained" fits was calculated, in which at least seven out of the eight SABRE beams were filled with backscatter and a rms error of less than $50 \mathrm{~m} / \mathrm{s}$ was required. A third set of tightly constrained fits were calculated which included the extra constraint than no l-o-s velocity anywhere in the field-of-view of either of the SABRE radars exceeded $500 \mathrm{~m} / \mathrm{s}$. The study concentrated on the direction of the velocity vectors, as velocity magnitude of both the merged and the beam-swung vectors were constrained due to sound speed limiting. $74 \%$ of the "loosely constrained" beam-swung angles lie inside a cone of $45^{\circ}$ half-width around the SABRE merged velocities with $82 \%$ of the tightly constrained l-o-s velocities and $84 \%$ of the filtered 1-o-s velocity lying within a cone of $45^{\circ}$ halfwidth. This compares with $48 \%$ of the SuperDARN beamswung vectors and $84 \%$ of the "fitted" map-potential vectors observed in the dawn sector within $65^{\circ}$ and $70^{\circ}$ latitude. Thus the SABRE filtered beam-swung vectors are as effective at mapping the direction of ionospheric flow as the "true" map-potential vectors at low latitudes in the dawn sector. We believe that SuperDARN beam-swung vectors are less successful at mapping the direction of ionospheric flow than the SABRE vectors because SABRE was a VHF radar observing mainly low-latitude return flow in the E-region, while SuperDARN is a HF radar observing at higher latitudes where HF radar suffers from problems of HF noise and misidentified ground scatter. Also beam-swinging assumes a homogeneous flow along the L-shells; as SABRE has a much smaller field-of-view than the SuperDARN radars there will be less variation in the flow across it.

\section{Summary}

This study has entailed a comparison of the merged, map-potential (1998 version), L-shell "fitting" and beamswinging techniques when predicting the ionospheric flow vectors using 1-o-s velocity data from the SuperDARN HF radars. For the first time, quantitative information has been provided about the validity of the map-potential technique, which is becoming the main source of real-time information about global convection. We can conclude that the map-potential model is significantly more successful than the beam-swinging technique at estimating both the magnitude and the direction of the convection flow vectors, even when the beam-swung vectors are filtered using an rms error analysis. The quality of the fit is dependent on location and time of day, with the "fitted" and "true" map-potential vectors predicting the direction of the flow most successfully at low latitudes in the day sector. There is no significant difference in the ability of the "true" or "fitted" map-potential vectors to recreate the direction of convective flow vectors but the "true" map-potential vector re-creates the magnitude of the convective flow vectors more successfully than the "fitted" vectors.

Acknowledgements. CUTLASS is supported by the Particle Physics and Astronomy Research Council (PPARC grant PPA/R/R/1997/00256), UK, the Swedish Institute for Space Physics, Uppsala, and the Finnish Meteorological Institute, Helsinki. GP is supported by PPARG grant PPA/G/O/1999/00181. 
The authors wish to thank C. Senior and J.-C. Cerisier for developing the SuperDARN merging software.

The Editor in Chief thanks J. Holt for his help in evaluating this paper.

\section{References}

André, D., McNamara, A. G., Wallis, D. D., McIntosh, B. A., Hughes, T. J., Sofko, G. J., Koehler, J. A., McDiarmid, D. R., Prikryl, P., and Watermann, J.: Diurnal radio aurora variations at $50 \mathrm{MHz}$ measured by the Bistatic Auroral Radar System radars, J. Geophys. Res., 8651-8661, 1988.

Bristow, W. A., Ruohoniemi, J. M., and Greenwald, R. A.: Super Dual Auroral Radar Network observations of convection during a period of small-magnitude northward IMF, J. Geophys. Res., 103, 4051-4061, 1998.

Davies, J. A., Lester, M., Milan, S. E., and Yeoman, T. K.: A comparison of F-region ion velocity observations from the EISCAT Svalbard and VHF radars with irregularity drift velocity measurements from the CUTLASS Finland HF radar, Ann. Geophysicae, 18, 589-594, 2000.

Davies, J. A., Lester, M., Milan, S. E., and Yeoman, T. K.: A comparison of velocity measurements from the CUTLASS Finland radar and EISCAT UHF system, Ann. Geophysicae, 17, 892902, 1999.

Fejer, B. G. and Kelley, M. C.: Ionospheric irregularities, Rev. Geophys., 18, 401-454, 1980.

Freeman, M. P., Ruohoniemi, J. M., and Greenwald, R. A.: The determination of time-stationary two-dimensional convection patterns with single-stations radars, J. Geophys. Res, 96, 15735$15749,1991$.

Greenwald, R. A., Weiss, W., Nielsen, E., and Thomson, N. R.: STARE: A new radar auroral backscatter experiment in northern Scandinavia, Radio Sci., 13, 1021-1039, 1978.

Greenwald, R. A., et al.: DARN/SuperDARN: A global view of high-latitude convection, Space Sci. Rev., 71, 761-796, 1995.

Hanuise, C., Senior, C., Cerisier, J.-C., Villain, J.-P., Greenwald, R. A., Ruohoniemi, J. M., and Baker, K. B.: Instantaneous mapping of high-latitude convection with coherent HF radars, J. Geophys. Res, 98, 17 387-17400, 1993.

Jackson, J. D.: Classical Electrodynamics, John Wiley, New York, 1962.

Kofman, W. and Nielsen, E.: STARE and EISCAT measurements: Evidence for the limitation of STARE Doppler velocity observations by the ion acoustic velocity, J. Geophys. Res., 95, 19131$19135,1990$.

Lepping, R. P., et al.: The WIND magnetic field investigation, Space. Sci. Rev., 71, 207-229, 1995.

Lester, M., de la Beujardière, O., Foster, J. C., Freeman, M. P., Lühr, H., Ruohoniemi, J. M., and Swider, W.: The response of the large scale ionospheric convection pattern to changes in the IMF and substorms: Results from the SUNDIAL 1987 campaign, Ann. Geophysicae, 11, 556-571, 1993

Nielsen, E. and Schlegel, K.: A first comparison of STARE and EISCAT electron drift velocity measurements, J. Geophys. Res., 88, 5745-5750, 1983.

Nielsen, E. and Schlegel, K.: Coherent radar Doppler measurements and their relationship to the ionospheric electron drift velocity, J. Geophys. Res., 90. 3498-3504, 1985.

Nielsen, E., Guttler, W., Thomas, E. C., Steward, C. P., Jones, T. B., and Hedburg, A.: SABRE - A new radar auroral backscatter experiment, Nature, 304, 712-714, 1983.

Richmond, A. D and Kamide, Y.: Mapping electrodynamic features of the high-latitude ionosphere from localized observations: Technique, J. Geophys. Res., 93, 5741-5759, 1988.

Robinson, T. R.: Towards a self-consistent non-linear theory of radar auroral backscatter, J. Atmos. Terr. Phys., 48, 417-422, 1986.

Ruohoniemi, J. M., Greenwald, R. A., Baker, K. B., Villain, J.-P., and McCready, M. A.: Drift motions of smallscaleirregularitiesin the high-latitude F-region: An experimental comparison with plasma drift motions, J. Geophys. Res., 92, 4553-4564, 1987.

Ruohoniemi, J. M., Greenwald, R. A., Baker, K. B., Baker, K. B., Villain, J.-P., Hanuise, C., and Kelley, J.: Mapping high-latitude plasma convection with coherent HF radars, J. Geophys. Res., 94, 13 463-13 477, 1989.

Ruohoniemi, J. M. and Greenwald, R. A.: Statistical patterns of high-latitude convection obtained from Goose Bay HF radar observations, J. Geophys. Res., 101, 21 743-21 763, 1996.

Ruohoniemi, J. M. and Baker, K. B.: Large-scale imaging of highlatitude convection with Super Dual Auroral Radar Network HF radar observations, J. Geophys. Res., 103, 20 797-20 811, 1998.

Shepherd, S. G. and Ruohoniemi, J. M.: Electrostatic potential patterns in the high-latitude ionosphere constrained by SuperDARN measurements, J. Geophys. Res., 105, 23 005-23 014, 2000.

Villain, J.-P., Caudal, G., and Hanuise, C.: A SAFARI-EISCAT comparison between the velocity of F-region small-scale irregularities and the ion drift, J. Geophys. Res., 90, 8433-8443, 1985.

Villain, J.P., Greenwald, R. A., Baker, K. B., and Ruohoniemi, J. M.: HF radar observations of E-region plasma irregularities produced by oblique plasma streaming, J. Geophys. Res, 92, 12 327-12 342, 1987.

Weimer, D. R.: Models of high-latitude electric potentials derived with a least error fit of spherical harmonic coefficients, J. Geophys. Res., 100, 19595-19607, 1995.

Yeoman, T. K., Mattin, N., Ruohonirmi, J. M., Lester, M., and Pinnock, M.: An assessment of the L-shell fitting Beam-Swinging Techniques for Measuring Ionospheric E-Region Irregularity Drift Plasma, J. Geophys. Res., 97, 14 885-14 896, 1992. 